\title{
MEMAKNAI NILAI-NILAI SOSIAL PADA NOVEL NAPAS MAYAT KARYA BAGUS DWI HANANTO
}

\author{
Ari Musdolifah \\ Universitas Balikpapan \\ ary.musdolifah@uniba-bpn.ac.id
}

\begin{abstract}
ABSTRAK
Penelitian ini bertujuan untuk memaknai nilai-nilai sosial pada novel Napas Mayat karya Bagus Dwi Hananto dengan mendeskripsikan: (a) amanat cerita yang disampaikan oleh pengarang (b) pudarnya nilai sosial yang melatari novel Napas Mayat karya Bagus Dwi Hananto (c) temuan yang terkait dengan nilai pendidikan dalam novel Napas Mayat karya Bagus Dwi Hananto. Penelitian ini menggunakan pendekatan kualitatif dengan metode deskriptif dengan analisis data yang mengacu pada pendekatan sosiologi karya sastra. Hasil penelitian ini menunjukkan bahwa amanat cerita yang disampaikan pengarang dalam novel Napas Mayat karya Bagus Dwi Hananto adalah pentingnya menjunjung tinggi nilai sosial dalam kehidupan bermasyarakat dengan meningkatkan nilai kasih sayang dan kerukunan antarumat manusia. Pudarnya nilai sosial pada novel Napas Mayat karya Bagus Dwi Hananto adalah krisis nilai kasih sayang dan kerukunan. Temuan penelitian menunjukkan bahwa novel ini memuat nilai pendidikan, yaitu nilai moral.
\end{abstract}

Kata kunci: Sosiologi sastra, nilai-nilai sosial, novel, nilai, pendidikan

\begin{abstract}
This study aims to interpret social values in the novel Napas Mayat by Bagus Dwi Hananto by describing: (a) the mandate of the story conveyed by the author (b) the social value underlying the novel Napas Mayat by Bagus Dwi Hananto (c) findings related to the value of education in the novel Napas Mayat by Bagus Dwi Hananto. This study uses a qualitative approach with descriptive method with data analysis which refers to the sociological approach to literature. The results of this study indicate that the mandate story told by the author of the novel Napas Mayat by Bagus Dwi Hananto is the importance of upholding the social values in society by increasing the value of compassion and human interfaith harmony. The loss of social values in the novel Napas Mayat by Bagus Dwi Hananto is a crisis of values of love and harmony. Research findings show that this novel contains the value of education, namely moral values.
\end{abstract}

Keywords: Sociology of literature, social values, novels, values, education 


\section{PENDAHULUAN}

Sastra adalah suatu bentuk ekspresi pengarang dalam mengungkapkan perasaannya tentang realita dan masalah-masalah kehidupan secara mendalam dan spontan (Rokhmansyah, 2014:2). Realita dan masalah kehidupan tersebut disajikan secara indah di dalam sebuah karya sastra. Segala bentuk peristiwa dalam dunia realita di proses melalui tahap kontemplasi. Kontemplasi itu sendiri adalah kegiatan perenungan pengarang untuk menggabungkan dunia realita dengan dunia imajinasi. Dengan demikian, sastra adalah cerminan realita kehidupan yang disajikan berdasarkan pengalaman hidup pengarang.

Karya sastra merupakan karangan yang baik untuk melukiskan sesuatu tentang kehidupan manusia yang terkait dengan nilai-nilai. Salah satu karya sastra tersebut adalah novel. Novel merupakan suatu bentuk media yang penting dalam melukiskan nilai-nilai yang merupakan cermin kehidupan. Nilai tersebut bukan hanya nilai sosial tetapi juga nilai religius, nilai pendidikan, dan nilai budaya. Namun dalam penelitian ini, peneliti fokus kepada nilai sosial yang terdapat dalam novel.

Salah satu novel yang mencerminkan nilai sosial adalah novel Napas Mayat karya Bagus Dwi Hananto. Novel ini menceritakan tentang pudarnya nilai sosial yang pada tokoh satu dengan tokoh lainnya. Nilai sosial yang telah pudar tersebut adalah nilai kasih sayang dan nilai kerukunan. Pudarnya nilai sosial tersebut tampak pada perilaku tokoh yang melakukan tindakan kriminal, ketidakharmonisan hubungan antara tokoh satu dengan tokoh yang lainnya, penghinaan, dan lain sebagainya.

Novel Napas Mayat karya Bagus Dwi Hananto merupakan salah satu dari sekian banyak novel Indonesia yang mengangkat tema tentang kehidupan sosial. Salah satu novel yang mengusung tema sosial adalah novel Bekisar Merah karya Ahmad Tohari. Novel ini menceritakan tentang kritik-kritik sosial yan dikemukakan oleh pengarang terhadap berbagai bentuk penyimpangan yang ada dalam masyarakat.

Sastra yang bertemakan sosial sangat baik manfaatnya dalam bidang pendidikan. Kebebasan dalam bereskpresi yang dilakukan oleh pengarang menjadikan sastra sebagai cerminan masyarakat pada jamannya. Hal tersebut menjadikan sastra sebagai media penanaman karakter bagi pertumbuhan peserta didik. Oleh sebab itu, amanat dalam karya sastra adalah sebagai penguat bagi setiap manusia untuk berprilaku dalam kehidupan bermasyarakat. 
Berdasarkan uraian tersebut, peneliti akan meneliti nilai sosial untuk mendapatkan gambaran secara utuh terkait dengan memaknai nilai-nilai sosial pada novel Napas Mayat karya Bagus Dwi Hananto. Dengan demikian, permasalahan yang dikaji dalam penelitian ini adalah (a) amanat cerita yang disampaikan oleh pengarang (b) pudarnya nilai sosial yang melatari novel Napas Mayat karya Bagus Dwi Hananto (c) temuan yang terkait dengan nilai pendidikan dalam novel Napas Mayat karya Bagus Dwi Hananto.

\section{METODE PENELITIAN}

Sumber data dalam penelitian ini adalah novel Napas Mayat karya Bagus Dwi Hananto. Novel ini diterbitkan oleh PT Gramedia Pustaka Utama pada tahun 2015. Novel ini berjumlah 185 halaman beserta biografi pengarang dan ucapan terima kasih pengarang. Novel ini menjadi pemenang ketiga dalam sayembara menulis novel oleh Dewan Kesenian Jakarta.

Penelitian ini menggunakan pendekatan kualitatif dengan metode deskriptif. Data dalam penelitian ini dikumpulkan melalui proses pembacaan novel untuk mengarah kepada satuan-satuan cerita yang terkait dengan masalah penelitian. Analisis data dalam penelitian ini menggunakan pendekatan sosiologi sastra melalui sosiologi karya sastra. Sosiologi karya sastra digunakan untuk mendeskripsikan amanat cerita dalam novel Napas Mayat karya Bagus Dwi Hananto.

Teknik pengumpulan data dalam penelitian ini adalah teknik studi pustaka dengan membaca keseluruhan teks novel Napas Mayat karya Bagus Dwi Hananto yang terkait dengan masalah dalam penelitian. Selain itu, peneliti menggunakan teknik catat untuk mencatat masalah yang terkait dengan masalah penelitian.

\section{PEMBAHASAN}

\section{Amanat Cerita yang Disampaikan Pengarang}

Novel Napas Mayat mengisahkan tokoh Aku yang sewaktu kecil hidup dalam kemewahan. Orang tuanya selalu mengadakan pesta sehingga wanita dan kekuasaan dengan mudah diraihnya. Namun setelah Ayahnya bangkrut, sedikit demi sedikit teman yang dulu menjadi sahabat Ayahnya meninggalkannya. Tidak lama setelah itu, orang tuanya meninggal dunia dan tokoh Aku hidup sendiri. Dalam kesendirian 
tersebut, tokoh Aku mengalami penuaan dini sehingga menutup diri karena ia selalu dihina kuntet dan botak oleh orang-orang disekitarnya.

Tokoh Aku hidup di dalam apartemen yang kotor dan ditemani oleh anjing Pak Malikan tetangganya. Ia bekerja di perusahaan sebagai pemilah kertas. Pekerjaan itu ia lakukan selama bertahun-tahun.

Hidup dalam kekecewaan dan kesendirian membuat tokoh Hitam datang dalam hidupnya. Tokoh Hitam ini adalah bagian dari sisi buruk tokoh Aku yang selalu membujuknya untuk melakukan tindakan di luar batas kemanusiaan.

Di apartemen tersebut, tokoh Aku tinggal bersama Mama Besar yang bertubuh besar seperti gajah dan tidur seperti beruang kutub. Mama Besar ini selalu menghina fisik tokoh Aku secara terus menerus hingga tokoh Aku memiliki niat untuk membunuh Mama Besar. Tokoh Aku yang telah dikuasai tokoh Hitam akhirnya membunuh Mama Besar dan memakan dagingnya untuk meninggalkan jejak. Tidak hanya itu saja, tokoh Aku juga memakan temannya sendiri yang bernama Marbun karena suka menghinanya. Semua pembunuhan itu dilakukan tokoh Aku dengan amat rapi seperti pembunuh professional. Kepala Marbun dan Mama Besar disimpannya di dalam toples dan dimasukkan ke dalam lemari es.

Kemudian, tokoh Aku bertemu dengan Sarah yang merupakan atasan ditempatnya bekerja. Tokoh aku dan Sarah akhirnya memiliki hubungan spesial. Sarah juga mengalami nasib yang sama dengan tokoh Aku karena sama-sama dikecewakan oleh kehidupan. Sarah adalah seorang perempuan yang telah menikah, tetapi suaminya berselingkuh dengan wanita muda. Hal tersebut membuat tokoh Aku merasa kasihan kepada Sarah dan akhirnya membunuh suami Sarah tersebut.

Selanjutnya, tokoh aku bertemu dengan Novia. Novia adalah cinta pertama tokoh Aku. Novia mengingatkan tokoh aku bahwa di dunia ini masih ada yang mencintai dan menyayangi tokoh Aku dengan tulus.

Tidak lama setelah itu, tokoh Aku mengalami kecelakaan yang membuatnya harus dirawat di rumah sakit. Pada saat dirawat tersebut, tokoh Aku mengalami masa Limbo. Pada saat masa limbo itulah akhirnya tokoh Aku menyadari kesalahannya. Dan tokoh Aku berjanji jika setelah ia keluar dari Limbo, maka ia akan menyerahkan dirinya ke polisi untuk mengakui kesalahannya selama ini. Tokoh aku menyadari bahwa Novia masih mecintainya. Selain itu, tokoh aku juga menyadari bahwa ia salah 
dalam mengartikan makna kehidupan. Tokoh Aku akhirnya menjalani hukuman mati dan ia siap menanggungnya.

Amanat pengarang untuk pembaca adalah agar selalu menjunjung tinggi pentingnya nilai-nilai sosial dalam kehidupan sosial. Oleh sebab itu, penting bagi manusia untuk dapat menghargai perbedaan fisik orang lain apapun itu bentuknya.

Salah satu amanat pengarang terkait dengan menghargai perbedaan fisik orang lain tercermin dalam sikap tokoh yang bernama Armand kepada tokoh Aku dalam novel Napas Mayat karya Bagus Dwi Hananto berikut.

"Ia membantuku bangun dengan menarik lenganku. Ia pemuda baik yang tidak melihat kepalaku tapi hanya menunduk. Hobinya lari pagi di sini. Ia akan lari sampai ke ujung pantai ini dan kembali lagi dan lari lagi selama kurang lebih tiga jam dan dengan cara itulah ia jadi pemuda sehat yang tampak dari fisiknya. Namanya Armand dan ia tinggal tidak jauh dari pantai. Seseorang yang tidak merendahkanku dengan pandangan matanya” (Napas Mayat, 2015:70).

Kutipan teks di atas memberikan gambaran bahwa tokoh Armand melakukan komunikasi dengan tokoh Aku. Tokoh Aku yang selama ini selalu dikucilkan karena fisiknya merasa bahagia karena masih ada seseorang yang ingin berbicara dengannya. Pengarang ingin menyampaikan pesan bahwa setiap manusia memiliki perbedaan dengan manusia yang lainnya. Tidak semua manusia itu jahat dan tidak semua manusia itu baik. Dengan hadirnya tokoh Armand, pengarang memberikan pesannya bahwa setiap manusia wajib menghargai orang lain. Meskipun, seseorang tersebut buruk rupa. Dengan adanya sikap tersebut, maka seseorang tidak akan merasa rendah diri karena fisiknya dan akan merasa bahagia.

Selain itu, amanat pengarang dalam novel Napas Mayat karya Bagus Dwi Hananto berikut tergambar pada kutipan berikut.

“Air mata menetes membuat noda kelam di rok Sarah. Angin sepoi-sepoi menjatuhkan daun-daun. Ia dikalahkan oleh kecantikan. Apakah kecantikan dan ketampanan itu bisa diukur? Memang seperti itukah orang dikatakan cantik. Kulit putih yang mulus, buah dada yang kencang dan sempurna, wajah dengan bibir tipis dan mata yang menggoda, hidung mancung, rambut yang tebal dan indah-siapa yang menentukan itu? Tuhan? Bukan. Itu mata manusia yang tidak melihat lebih dalam bahwa ada kecantikan yang benar jika ia memasuki jiwa manusia. Tapi bagaimana mungkin manusia bisa melihat jiwa manusia lain? Mereka hanya mencintai tubuh. Mereka tidak 
bisa meninggalkannya. Kami tidak bisa meninggalkan tubuh yang bagi kami sempurna itu. Manusia yang hanya bisa melihat luaranya saja” (Napas Mayat, 2015:78-79).

Kutipan teks di atas memberikan gambaran bahwa pengarang mengemukakan adanya penilaian fisik dari manusia kepada manusia yang lain. Penilaian tersebut didasarkan atas indikator-indikator tertentu yang diciptakan oleh manusia itu sendiri. Padahal, semua manusia itu sama di mata Tuhan. Tuhan menciptakan manusia dengan segala macam kekurangan dan kelebihannya masing-masing. Oleh sebab itu, manusia berbeda dengan manusia yang lainnya. Harusnya, manusia menyadari hal itu dan memberikan kasih sayang yang sama dengan manusia yang lain tanpa ada perbedaan.

\section{Pudarnya Nilai sosial yang Melatari Novel Napas Mayat Karya Bagus Dwi Hananto}

Pudarnya nilai sosial yang terdapat dalam novel Napas Mayat karya Bagus Dwi Hananto adalah pudarnya nilai sosial dengan jenis kasih sayang dan kerukunan. Pudarnya nilai kasih sayang sesama umat manusia digambarkan dalam novel ini dengan tidak adanya rasa kasih sayang antara tokoh aku dengan Mama Besar dan teman-teman kuliah tokoh Aku. Hal tersebut ditandai dengan adanya penghinaan fisik yang dilakukan oleh Mama Besar dan teman-teman tokoh Aku kepada tokoh aku. Akibatnya, tokoh aku merasa sendirian di dunia dengan perasaan kecewa, dendam, dan sedih. Berikut adalah adalah gambaran pudarnya nilai-nilai sosial tersebut.

"Mama Besar, tubuh gajah memenuhi pintu, hari ini berkata, "Si Aneh sudah pulang dari kerja, haha! Apa yang kau bawa selain wajah buruk dengan tiga helai rambut tipis itu?” (Napas Mayat, 2015:15-16).

Kutipan teks di atas menggambarkan bahwa Mama Besar sedang menghina fisik tokoh Aku. Mama Besar merupakan pemilik apartemen tempat tokoh Aku tinggal. Mama Besar merasa bahagia dengan celaan yang diberikan kepada tokoh Aku.

Selain itu, tokoh Aku juga mengalami hinaan dari teman-temannya sewaktu kuliah. Berikut adalah kutipannya. 
"Pada saat kuliah aku merasa asing dengan kehidupan akademik di sana. Orang-orang selalu melihatku dengan pandangan janggal karena aku seorang pemuda yang dilanda botak. Aku tetap bertahan dan pada malam-malam aku berserapah menghardik mereka yang telah menatap hina padaku itu. Asu! Aku tidak bisa membalas apapun selain mereka tidak punya kekurangan yang menonjol di luar dirinya, juga bahwa mereka tidak salah. Kebotakanku menarik perhatian mereka. Tentu saja mereka pasti akan melihat. Beberapa yang sadar dan dungu akan mencela, yang lain yang iba hanya akan membiarkanku dalam jam-jam memalukan yang terus kutempuh demi meraih gelar. Aku belajar tanpa niat, dikalahkan kejayaan dalam masa tua yang terburu, dalam karma dosa-dosa tanpa penyembahan. Seperti seorang colonel dalam kisah fantastis karangan Gabriel Garcia Manjuez. Kemudian aku lebih menyibuki diri pada buku buku dan terus membaca dan membaca mencoba melampaui bacaanku. Orang pertama yang ingin kubunuh kala itu adalah Tiga Gadis Bangkai dan yang kedua seorang sahabat dekatku yang kini sudah tidak berkomunikasi lagi denganku” (Napas Mayat, 2015:37-38).

Kutipan teks di atas menggambarkan bahwa tokoh Aku mengalami hinaan dari teman-temannya semasa kuliah. Ia dihina karena botak dan tidak seorang pun yang kasihan padanya baik itu sahabatnya sendiri.

Pudarnya nilai sosial yang berupa pudarnya kasih sayang antara Mama Besar dan Marbun kepada tokoh Aku tersebut membuat hubungan sosial antara mereka menjadi tidak harmonis. Akibatnya, kerukunan antara mereka pudar. Tidak adanya sikap saling menghormati yang diberikan kepada Mama Besar dan teman-teman kuliah tokoh Aku kepada tokoh Aku berujung dengan konflik sehingga memunculkan tindakan kriminal yang dilakukan oleh tokoh Aku.

Dari segi sosial, tokoh Aku dapat hidup dengan layak seperti manusia normal lainnya. Hal tersebut akan berhasil apabila lingkungan sosialnya tidak memperlakukannya secara berbeda dengan manusia yang lainnya. Dengan keadaan fisik yang berbeda tersebut, lingkungan sosial di mana sebagai tempat penerimaan manusia satu dengan manusia yang lainnya harus memberikan kasih sayang yang sama dengan manusia yang lainnya tanpa membedakan fisik, status, agama, ras, dan sebagainya. Dengan demikian, perasaan menarik diri manusia dengan manusia yang lainnya akan hilang.

Selain itu, setiap manusia memiliki kekurangan dan kelebihan yang berbedabeda. Alangkah baiknya, jika kekurangan dan kelebihan dijadikan sebagai pedoman untuk bersikap baik kepada orang lain, seperti simpati, empati, peduli dan saling 
menghargai. Apabila, sikap-sikap tersebut dilestarikan maka kerukunan dalam lingkungan sosial akan terjaga. Dan juga, setiap manusia tidak akan diperlakukan berbeda dengan manusia yang lain dalam lingkungan sosialnya.

\section{Nilai Pendidikan dalam Novel Napas Mayat Karya Bagus Dwi Hananto}

Berdasarkan hasil analisis terhadap novel Napas Mayat karya Bagus Dwi Hananto dapat ditemukan nilai pendidikan dalam novel. Secara umum, nilai yang ditemukan adalah sebagai berikut.

(1) Pengarang menyampaikan nilai pendidikan dalam bentuk nilai moral kepada pembaca. Moral adalah ajaran tentang baik dan buruk yang diterima mengenai perbuatan, sikap, berkewajiban, dan sebagainya (Fitriati, 2015:108-111). Nilai moral yang tercermin pada novel Napas Mayat karya Bagus Dwi Hananto adalah pada sikap tokoh berikut.

"karena dendamku pada manusia ini membutakan diriku," kataku. Aku sudah tidak tahan. Dan setelah membunuh orang yang pertama, aku merasakan hasratku akan daging. Tapi kini aku telah berdosa dan memohon ampun. Makanya aku mesti bergegas menguburkan kepala-kepala ini supaya mereka bisa kembali ke asalnya, tidak menyimpan dendam lagi” (Napas Mayat, 2015:134-135).

Kutipan teks di atas menggambarkan bahwa tokoh aku menyadari kesalahannya karena telah membunuh tiga orang dalam hidupnya, yaitu Mama Besar, Marbun, dan suami dari tokoh Sarah. Ia berpikir bahwa perbuatannya itu salah dan ia akan melaporkannya kepada pihak yang berwajib.

Tokoh Aku memiliki dendam terhadap orang-orang yang telah menghina dirinya. Hal tersebut, ia tunjukkan dengan membunuh mereka. Pengarang menyampaikan pesan moral kepada pembaca bahwa tindakan terpuji adalah berani mengakui kesalahan dan menjauhi perbuatan-perbuatan keji, seperti membunuh, menghina, dan tidak mengakui kesalahan yang diperbuat.

Nilai moral sangat penting dalam kehidupan sosial. Dengan adanya nilai moral, maka akan timbul perasaan kepedulian dan empati kepada manusia yang satu dengan manusia yang lain. Dengan demikian, akan tercipta kerukunan dan kasih sayang antarumat manusia. Nilai moral harus selalu ditanamkan kepada 
manusia sejak dini untuk membentuk karakternya dalam menilai kehidupan agar dapat memilih hal-hal yang baik dan yang buruk dalam kehidupannya.

(2) Pengarang menyampaikan pentingnya menjunjung tinggi nilai-nilai sosial dalam kehidupan sosial untuk mempersempit segala bentuk perilaku kriminal yang dapat merusak hubungan sosial antarumat manusia. Hal tersebut tercermin pada sikap tokoh Armand kepada tokoh Aku dalam novel Napas Mayat karya Bagus Dwi Hananto berikut.

“Anak? Mendengar itu aku merasa terharu. Anak adalah hal tidak pernah kupikirkan karena aku tidak ingin menikah dan tidak punya masa depan agar dibagi dengan seseorang dengan komitmen bersama. Anak. Armand memang seperti anak bagiku. Cara dia memperlakukan orang tua sebagai kawannya. Dunia yang bahagia miliknya ia bagikan padaku ketika kami pertama kali bertemu; saat dia membangunkanku kala aku terlelap di pantai ini dulu” (Napas Mayat, 2015:141).

Kutipan teks di atas menggambarkan bahwa tokoh Aku merasakan bahagia dalam dirinya. Ia berpikir bahwa kebahagiaan seseorang akan lebih indah apabila dibagi dengan orang lain. Dengan sikap tokoh Armand tersebut, tokoh Aku merasa dihargai, dihormati, dan disayangi yang tidak ia dapatkan dari manusia yang lain.

Pengarang ingin menyampaikan bahwa dengan adanya sikap saling menghormati, menghargai, dan menyayangi, maka hubungan antara manusia yang satu dengan yang lain akan terjalin dengan baik dan harmonis. Dengan demikian, konflik atau dendam yang merusak hubungan sosial akan terhindari.

\section{PENUTUP}

Berdasarkan hasil analisis dan pembahasan dapat disimpulkan sebagai berikut.

a. Amanat cerita yang disampaikan pengarang dalam novel Napas Mayat karya Bagus Dwi Hananto adalah pentingnya menjunjung tinggi nilai sosial dalam kehidupan bermasyarakat dengan meningkatkan nilai kasih sayang dan kerukunan antarumat manusia. Manusia harus diperlakukan sama dengan manusia yang lain tanpa membedakan suku, ras, fisik, agama, dan lain sebagainya. Dengan adanya nilai sosial terssbut maka konflik sosial tidak akan terjadi. 
b. Pudarnya nilai sosial pada novel Napas Mayat karya Bagus Dwi Hananto adalah krisis nilai kasih sayang dan kerukunan. Tokoh Aku yang dihina karena fisiknya oleh Mama Besar dan teman-teman kuliah tokoh Aku berdampak pada kondisi psikis tokoh Aku. Akibatnya, tokoh Aku melakukan tindakan kriminal dengan membunuh dan memakan jasad Mama Besar karena dendam yang amat kuat.

c. Temuan penelitian menunjukkan bahwa novel ini memuat nilai pendidikan, yaitu nilai moral. Nilai moral ini penting ditanamkan sejak dini agar manusia dapat memilih mana yang baik dan buruk dalam kehidupan dan bermasyarakat.

\section{DAFTAR RUJUKAN}

Aisah, Susianti. 2015. Nilai-Nilai Sosial yang Terkandung dalam Cerita Rakyat “Ence Sulaiman” pada Masyarakat Tomia. Jurnal Humanika. 3(15):5-7.

Faruk. 2014. Pengantar Sosiologi Sastra. Yogyakarta: Pustaka Pelajar.

Fitriati, Siti. 2015. Nilai-Nilai Pendidikan Novel "Sang Pemimpi” Karya Andrea Hirata. Jurnal Pesona. 1(2):104-116.

Hananto, Bagus Dwi. 2015. Napas Mayat. Jakarta: PT Gramedia Pustaka Utama.

Nurgiyantoro, Burhan. 2010. Teori Pengkajian Fiksi. Yogyakarta: Gadjah Mada University Press.

Rahmah dkk. 2015. Target Nilai 10 UN SMA/MA IPS 2016 Sistem CBT. Jakarta: Cmedia.

Rokhmansyah, Alfian. 2014. Studi dan Pengkajian Sastra (Perkenalan Awal terhadap Ilmu Sastra). Yogyakarta: Graha Ilmu.

Soeroso, Andreas. 2008. Sosiologi 1. Jakarta: Yudhistira. 